\title{
Oceanography and seabird foraging: within-season impacts of increasing sea-surface temperature on the Great Barrier Reef
}

\author{
S. J. Weeks ${ }^{1}$, C. Steinberg ${ }^{2}$, B. C. Congdon ${ }^{3, *}$ \\ ${ }^{1}$ Biophysical Oceanography Group, School of Geography, Planning and Environmental Management, \\ University of Queensland, St Lucia, Queensland 4072, Australia \\ ${ }^{2}$ Australian Institute of Marine Science, Townsville, Queensland 4810, Australia \\ ${ }^{3}$ Centre for Tropical Environmental \& Sustainability Science (TESS), School of Marine \& Tropical Biology, \\ James Cook University, PO Box 6811, Cairns, Queensland 4870, Australia
}

\begin{abstract}
Previously we have demonstrated that prey availability to seabirds of the Great Barrier Reef (GBR) decreases in direct association with within-season increases in sea-surface temperature, independent of prevailing El Niño conditions. These negative impacts occur throughout the GBR and affect multiple seabird species. Currently, the oceanic processes driving these impacts or the potential for them to occur in other marine systems are unknown. Here, we use satellite and in situ data obtained during a thermal stress event to identify the within-season links between ocean dynamics and seabird foraging success on the southern GBR. In February 2006, a major mesoscale eddy formed coastward of the East Australian Current flow, adjacent to our study site. In mid-February, strengthening of this eddy caused an intrusion of cool, dense waters at depth across the GBR shelf. This intrusion intensified vertical stratification and caused a pronounced warming of sea-surface layers. Prey availability to seabirds significantly decreased during this period and remained low until eddy intensity decreased and surface waters cooled. Prey availability increased following this episode, clearly indicating that loss of prey was associated with a short-term vertical and/or horizontal redistribution of forage-fish, or subsurface predators, rather than an overall decrease in productivity linked to seasonal-scale El Niño processes.
\end{abstract}

KEY WORDS: El Niño $\cdot$ Eddy dynamics $\cdot$ Wedge-tailed shearwater $\cdot$ Ardenna pacifica $\cdot$ Great Barrier Reef $\cdot$ Sea-surface temperature $\cdot$ East Australia Current $\cdot$ Climate change

\section{INTRODUCTION}

El Niño activity significantly influences seabird breeding participation and reproductive success on the Great Barrier Reef (GBR), Australia (Peck et al. 2004, Devney et al. 2009). In this region, intense El Niño events have been linked to almost total reproductive failure of impacted seabird nesting populations (Smithers et al. 2003, Peck et al. 2004). Some impacts that accompany intense El Niño conditions can be attributed to seasonal-scale changes in chlorophyll a concentrations (productivity) and thermocline characteristics that likely depress the seasonal recruitment of seabird prey species (Devney et al. 2009). At this seasonal scale no influence of seasurface temperature (SST) on prey availability is apparent (Devney et al. 2009). In general, seasonalscale impacts on overall productivity are consistent with models of how El Niño intensity changes are thought to affect seabird reproductive success in 
other marine systems (Stenseth \& Mysterud 2002, Durant et al. 2003, Inchausti et al. 2003).

However, in addition to the seasonal-scale loss of prey associated with intense El Niño activity, we have also demonstrated that prey availability to seabirds of the GBR decreases in direct association with small-scale increases in SST, independent of prevailing El Niño conditions (Peck et al. 2004). These within-season relationships between SST and prey availability have been observed throughout the GBR for multiple seabird species across a number of sampling years and have been shown to significantly impact chick growth and other reproductive parameters (Peck et al. 2004, Erwin \& Congdon 2007, Congdon et al. 2007, Devney et al. 2010). During intense El Niño events these within-season impacts further exacerbate food shortages occurring due to seasonalscale declines in productivity (Peck et al. 2004). We have previously hypothesized that sea temperature likely reduces seabird access to prey species within seasons by affecting the vertical and/or horizontal distribution of prey or subsurface predators, rather than overall productivity (Peck et al. 2004), but this idea is untested. We are the first to document withinseason impacts occurring independent of prevailing El Niño conditions and so the potential for them to reduce food availability to seabirds in other marine systems is unknown, as are the oceanic processes driving them. We believe it likely that some impacts previously attributed only to El Niño-driven seasonal-scale changes in productivity may also involve these within-season phenomena, particularly in tropical systems.

Understanding the processes responsible for variation in resource availability to higher trophic levels, such as seabirds, is a priority for guiding informed management decisions. In turn, understanding the inherent variability in this requires much-improved knowledge of the linkages between the large-scale oceanography and the meso- to sub-mesoscale dynamics in the GBR region. Therefore, we used data associated with a thermal stress event on the southern GBR in the austral summer of 2005/2006 to identify the oceanographic processes responsible for within-season sea temperature impacts on prey availability to seabirds. Specifically, we used satellite and available in situ temperature data to examine how oceanographic dynamics influenced food availability to wedge-tailed shearwaters Ardenna pacifica during this period and provide a conceptual model of the key ecological role played by cyclonic mesoscale eddies that form on the coastward edge of the East Australian Current (EAC).

\section{DATA AND METHODS}

\author{
Satellite data
}

Satellite data were derived from the moderate resolution imaging spectroradiometer (MODIS) aboard the National Aeronautics and Space Administration (NASA) Terra and Aqua satellites (modis.gsfc.nasa .gov). Daily MODIS data were acquired from NASA (oceancolor.gsfc.nasa.gov) and time series of SST and chlorophyll a concentration ( $\mathrm{chl}$ a) images were produced at high spatial resolution $(1 \mathrm{~km})$ for the period from 2002 to 2008. Thermal data (day- and night-time) from both MODIS sensors were merged in the generation of the SST time series. Only MODIS-Aqua data were used for the chl a time series due to the unstable calibration of the MODIS-Terra ocean colour data over the lifetime of the mission (oceancolor.gsfc.nasa.gov/forum). For the purpose of this study, 2 sets of images were generated from the MODIS data. Daily SST and chl a images were generated for the southern GBR region (20 to $25^{\circ} \mathrm{S}, 149$ to $154^{\circ} \mathrm{E}$ ) for February 2006 to allow high temporal and spatial resolution during the thermal stress event. To investigate the linkages between large-scale oceanography and mesoscale dynamics, time series of monthly and weekly mean images were generated for the region 22 to $30^{\circ} \mathrm{S}, 150$ to $156^{\circ} \mathrm{E}$ for the period from 2002 to 2008 .

\section{Mooring data}

A mooring was deployed to the south of Heron Reef at $23^{\circ} 30.73^{\prime} \mathrm{S}, 151^{\circ} 57.21^{\prime} \mathrm{E}$ (Fig. 1) for the period from December 2005 to March 2006, in order to observe the thermal structure of the water column over the austral summer. Subsurface temperature loggers were placed on a vertical in-line mooring at depths of 4, 9, 19 and $35 \mathrm{~m}$ (lowest astronomical tide) in a total water column depth of $42 \mathrm{~m}$. Measurements were taken every $5 \mathrm{~min}$. Wind measurements were recorded from a buoy on the northern side of the neighbouring Wistari Reef located at $23^{\circ} 27.17^{\prime} \mathrm{S}, 151^{\circ} 53.01^{\prime} \mathrm{E}$.

\section{Seabird data}

Adult provisioning, chick growth and chick survival were monitored at 24 wedge-tailed shearwater Ardenna pacifica nests on Heron Island $\left(23^{\circ} 26^{\prime} \mathrm{S}\right.$, $\left.151^{\circ} 51^{\prime} \mathrm{E}\right)$, in the Capricorn-Bunker Section of the GBR Marine Park (Fig. 1), from 3 to 27 February 2006 


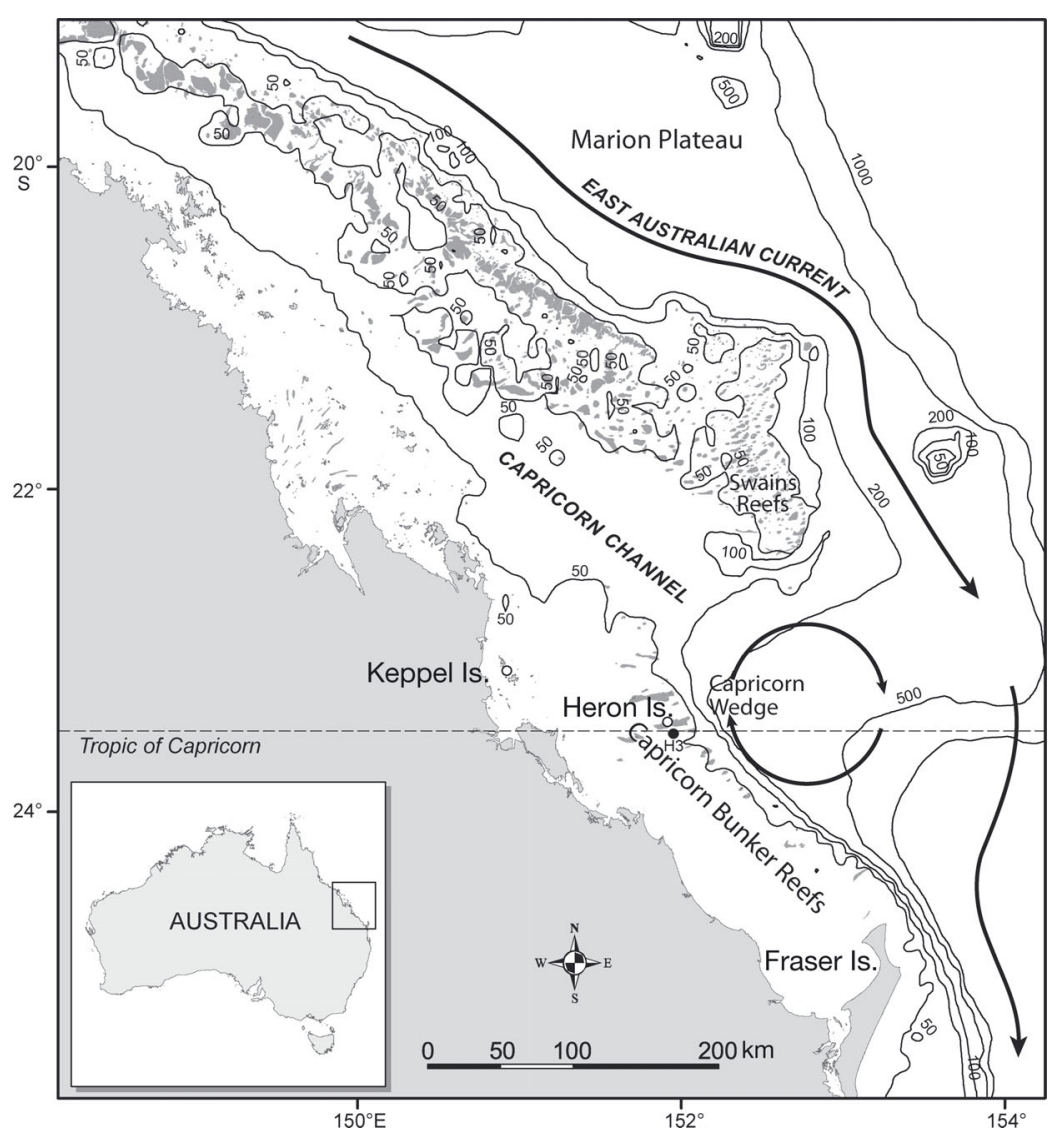

Fig. 1. A schematic map of the study area in the southern Great Barrier Reef, illustrating key bathymetric features, islands and coral reefs. The wavy arrows represent the southward flow of the East Australian Current. The circular arrows show the location of the Capricorn Eddy within an indentation of the $200 \mathrm{~m}$ isobath, referred to as the Capricorn Wedge. The filled circle on the Tropic of Capricorn (H3) shows the location of the vertical in-line mooring used in the study. Landmass and coral reefs are shaded in light grey

al. 2010) characteristically formed shoreward of the primary EAC flow in our region of interest $\left(22\right.$ to $30^{\circ} \mathrm{S}, 150$ to $\left.156^{\circ} \mathrm{E}\right)$. In the southern $\mathrm{GBR}$, the Capricorn Eddy (Fig. 1) is more easily defined using satellite observations in the cooler months, when the horizontal gradients in sea-surface properties are greater and more readily interpretable (Weeks et al. unpubl. data). Nevertheless, it is possible to identify this eddy feature in February 2006 using both satellite SST and ocean colour imagery (Fig. 2).

The in situ temperature loggers on the vertical in-line mooring to the south of Heron Reef showed a uniformly warm, tidally mixed water column during the early and late portions of February 2006 (Fig. 3a). This was interrupted by an abrupt intrusion of cooler waters at depth $(35 \mathrm{~m})$ that was sustained for $\sim 10 \mathrm{~d}$ (mid-February portion of the time series shown in Fig. 3a). High-frequency tidal variation was apparent in the temperature traces, with a semidiurnal temperature amplitude of up to $1^{\circ} \mathrm{C}$ during coincident spring tides. Wind stress was marginally lower (Fig. 3b) during the cool-water bottom intrusion, but not significant enough to explain the abrupt onset and termination of stratification experienced during mid-February 2006 (Fig. 3a). At the regional scale extensive warming of sur-

(Congdon et al. 2005, Peck \& Congdon 2005). In brief, at each burrow both adults were banded for individual recognition, and adult attendance was monitored continuously from 17:00 to 05:00 h daily. Outside of these times no adult visits or chick feeding events were observed. Chicks in experimental nests were weighed twice each day using an electronic balance $( \pm 0.1 \mathrm{~g})$, at $16: 00 \mathrm{~h}$ prior to adults returning and immediately following any adult visit to a nest. These procedures allowed 2 measures of adult foraging success to be calculated for each nest: adult feeding frequency and a daily meal size index.

\section{RESULTS}

Analysis of the satellite time series showed that a major mesoscale eddy, the Capricorn Eddy (Weeks et face waters coincided with the intrusion of cooler waters at depth in mid-February (Fig. 2d).

Local prey availability to the shearwaters, as measured by both feeding frequency and average daily meal size, varied significantly during February 2006. Both variables were highly correlated $\left(F_{1,21}=21.47\right.$, $\operatorname{adj} R^{2}=0.51, p=0.0001$ ). Poor foraging conditions were clearly evident from 13 to 20 February when SSTs were generally warmer throughout the southern GBR region (Fig. 2d), significantly fewer nests (arcsine proportion nests fed, mean \pm SE: $0.48 \pm$ 0.042) were provisioned each night during this period than during early ( 5 to 12 February, $0.92 \pm$ 0.042 ) or late (21 to 27 February, $0.80 \pm 0.045)$ February (ANOVA, $F_{2,20}=28.87, \mathrm{p}<0.0001$; Fig. 4 ), and average meal sizes were the smallest observed for the season ( 5 to 12 February, $15.03 \pm 1.76 \mathrm{~g} ; 13$ to 20 February, $10.49 \pm 1.75 g$; 21 to 27 February, $23.64 \pm$ 


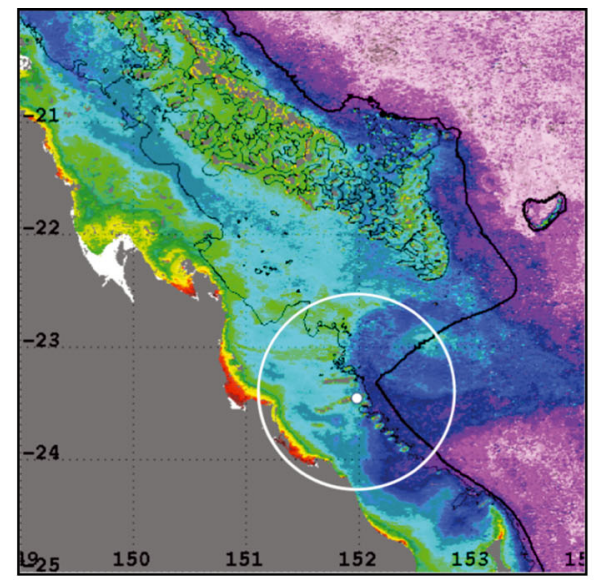

a) Chl a $\left(\mathrm{mg} \mathrm{m}^{-3}\right)$ for 2-10 February 2006

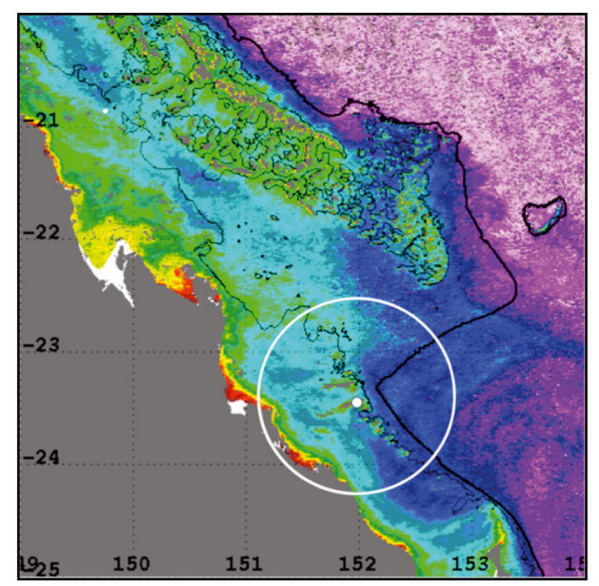

c) Chl a $\left(\mathrm{mg} \mathrm{m}^{-3}\right)$ for 11-19 February 2006

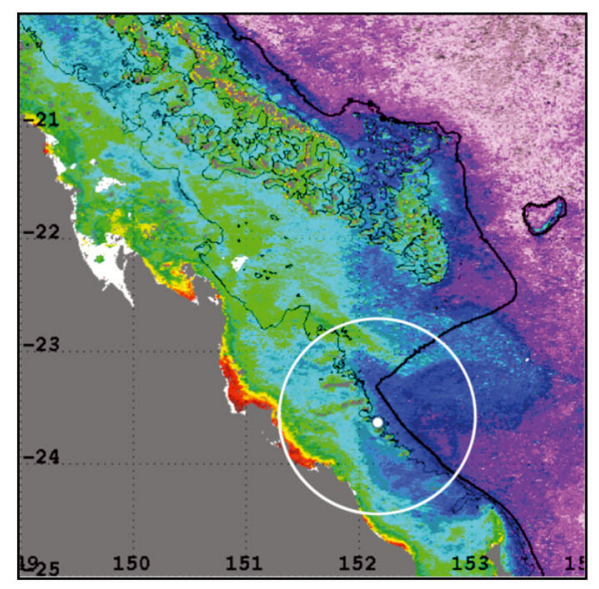

e) Chl a $\left(\mathrm{mg} \mathrm{m}^{-3}\right)$ for 21-28 February 2006

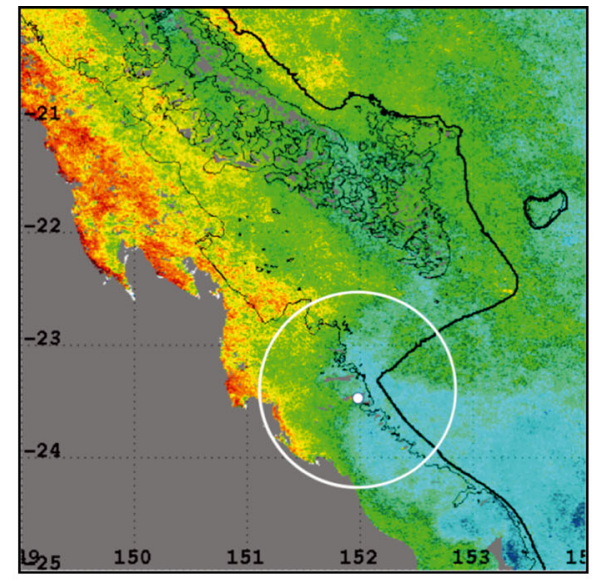

b) SST $\left({ }^{\circ} \mathrm{C}\right)$ for 2-10 February 2006

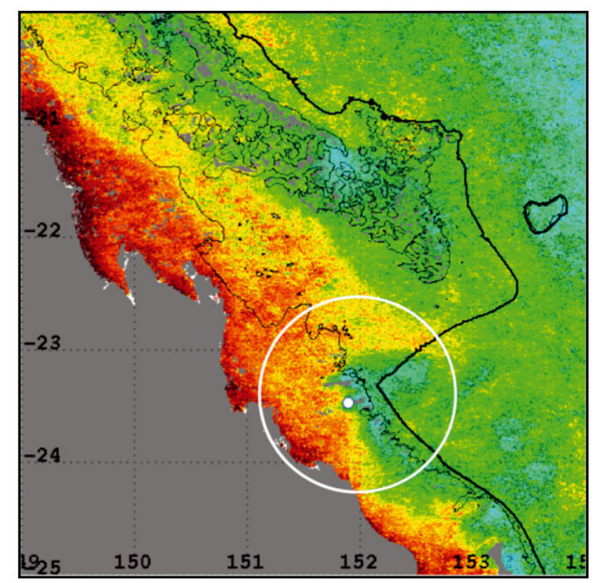

d) SST $\left({ }^{\circ} \mathrm{C}\right)$ for $11-19$ February 2006

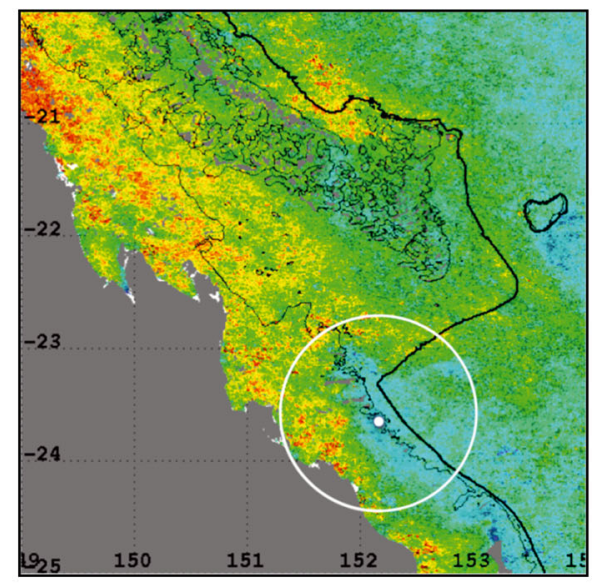

f) SST $\left({ }^{\circ} \mathrm{C}\right)$ for $21-28$ February 2006

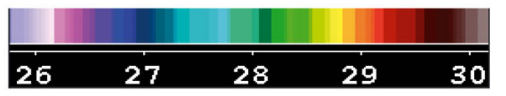

Fig. 2. Moderate resolution imaging spectroradiometer (MODIS) chl a and sea-surface temperature (SST) images for the southern Great Barrier Reef region $\left(20\right.$ to $25^{\circ} \mathrm{S}, 149$ to $154^{\circ} \mathrm{E}$ ) for February 2006. (a) Chl a (mg m ${ }^{-3}$ ) for 2 to 10 February 2006 ; (b) SST $\left({ }^{\circ} \mathrm{C}\right.$ ) for 2 to 10 February 2006; (c) chl a for 11 to 19 February 2006; (d) SST for 11 to 19 February 2006; (e) chl a for 21 to 28 February 2006; and (f) SST for 21 to 28 February 2006. The $200 \mathrm{~m}$ isobath line is the black contour line. The white circle includes the area within $100 \mathrm{~km}$ radius of Heron Island 

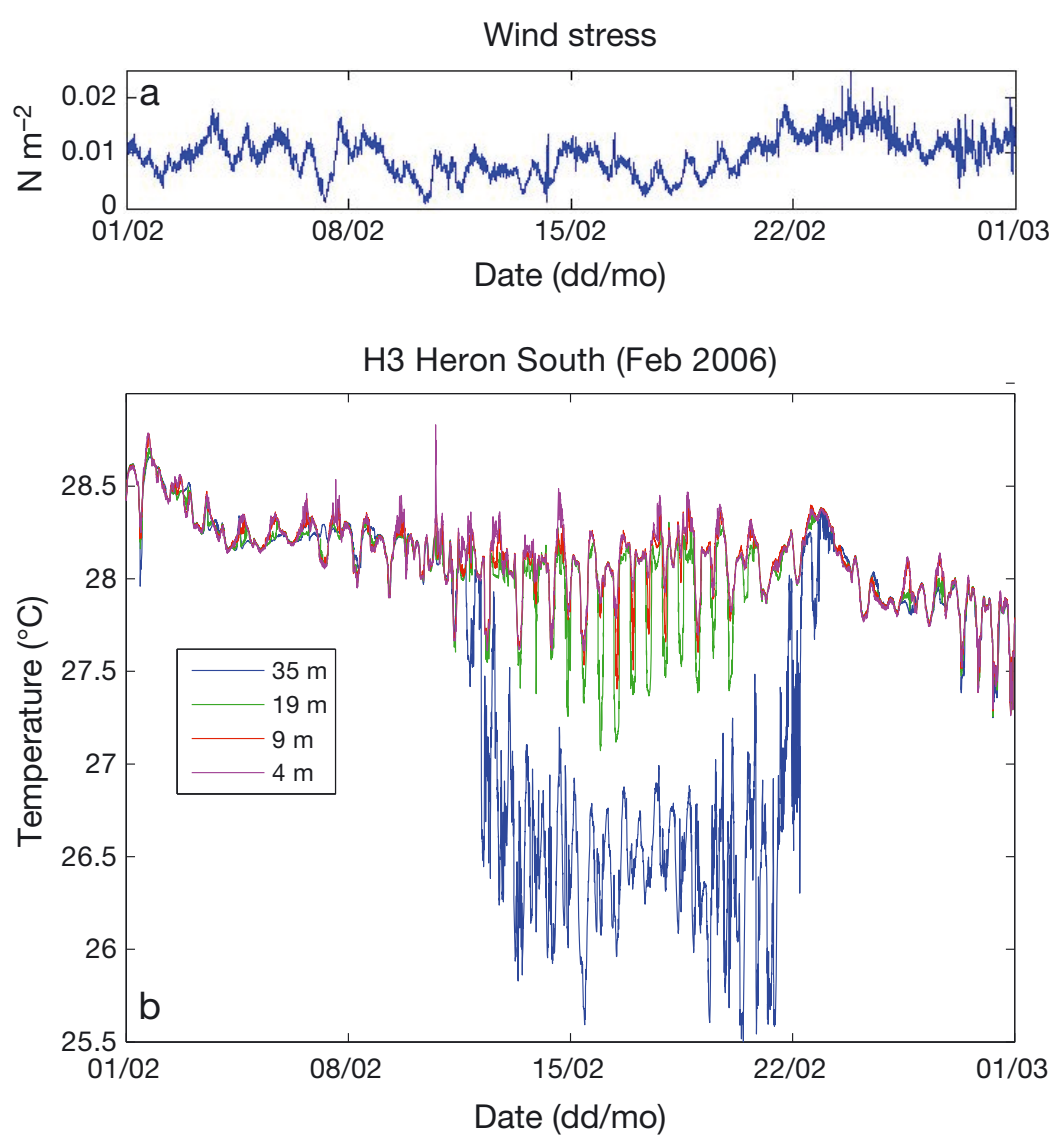

Fig. 3. (a) Wind stress measurements from nearby Wistari Reef show the effects of an intense low that mixed the water column. (b) Plot of temperature loggers placed at 4, 9, 19 and $35 \mathrm{~m}$ on the vertical in-line mooring (H3, see Fig. 1) in $42 \mathrm{~m}$ of water, south of Heron Island, February 2006. Temperature traces show the shelf waters are well mixed during the first and last portions of the month. A cold-water bottom intrusion is detected on the $35 \mathrm{~m}$ logger and persists for $11 \mathrm{~d}$, between 12 and 23 February. However, the loggers between $19 \mathrm{~m}$ and the surface remain well mixed throughout this period
1.88 g) February (ANOVA, $F_{2,20}=$ 13.30, $\mathrm{p}<0.0001$; Fig. 4). As in previous years (Peck et al. 2004), a negative relationship was observed between increasing average daily SST (as measured using the same regionalscale index Peck et al. 2004 used) and seabird prey availability (meal size: $F_{1,23}=4.70, \mathrm{R}^{2}=0.17, \mathrm{p}=0.041$; Fig. 5). In 2006 this relationship was slightly weaker than had been observed previously (Peck et al. 2004). At a more local scale, foraging success clearly decreased in association with a decrease in ocean temperature at $35 \mathrm{~m}$ (proportion of nests fed: $F_{1,21}=90.78, \mathrm{R}^{2}=$ $0.81, \mathrm{p}<0.001$; Fig. $6 \mathrm{c}$; meal size: $F_{1,23}=13.51, \mathrm{R}^{2}=0.37, \mathrm{p}=0.001$; Fig. 6d), but did not vary relative to changes in ocean temperature closer to the surface at $4 \mathrm{~m}$ (proportion of nests fed: $F_{1,21}=0.186, \mathrm{R}^{2}=0.009, \mathrm{p}=$ 0.671 ; Fig. $6 a$; meal size: $F_{1,23}=0.617$, $\mathrm{R}^{2}=0.026, \mathrm{p}=0.44 ;$ Fig. $6 \mathrm{~b}$ ).

\section{DISCUSSION}

The Capricorn Eddy was first noted in 1970 in a surface drifter study (Woodhead 1970). Subsequent oceanographic deployments and satellite SST studies have shown this lee eddy to trigger upwelling along the continental shelf (Kleypas \& Burrage 1994,

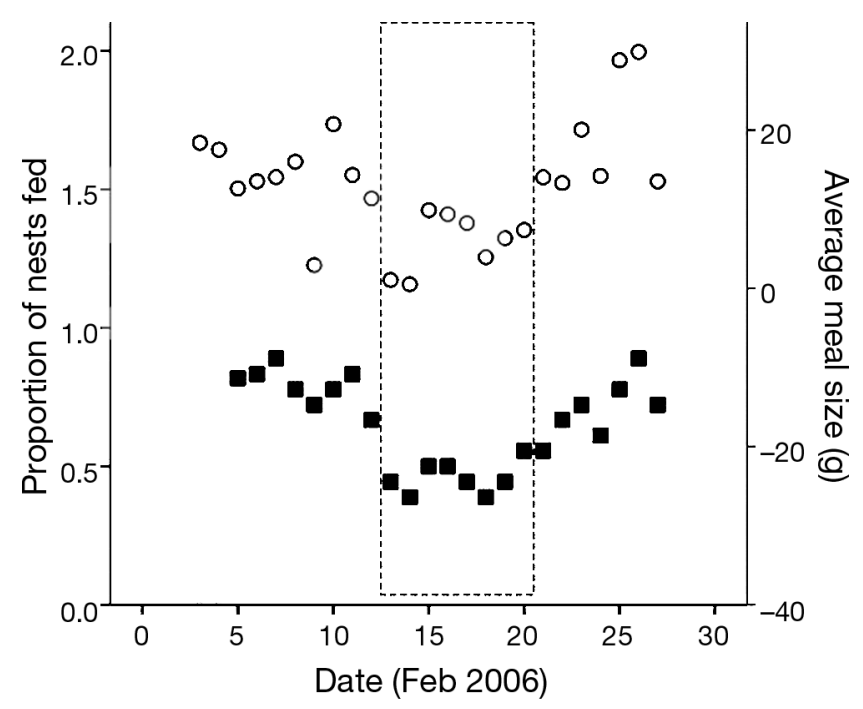

Middleton et al. 1994). During February 2006, the Capricorn Eddy was identified using both satellite SST and ocean colour imagery (Fig. 2). For example, from 2 to 10 February 2006 (Fig. 2a), low chl a (pink to deep blue) EAC waters were seen to intrude from the southeast along the outer continental shelf, flushing the southern Capricorn-Bunker reefs, to form a cyclonic (clockwise) lee eddy encircling a higher chl a signal. The cyclonic feature was similarly identified in the associated SST image (Fig. 2b), representing surface 'skin' temperature only (Brown \& Minnett

Fig. 4. Ardenna pacifica. Average daily meal mass $\left(g_{;} O\right)$ and proportion of nests fed per day ( $\square$ ) for wedge-tailed shearwater chicks at Heron Island from 3 to 27 February 2006. The boxed area indicates poor foraging conditions observed from $\sim 13$ to 20 February in conjunction with regional warming of sea-surface temperature, shown in Fig. $2 d$ 




Fig. 5. The relationship between regional sea-surface temperature (SST) and daily average meal size during the study period, generated according to Peck et al. (2004). Meal size was measured as the difference in chick mass between its 16:00 $\mathrm{h}$ weighing and mass immediately following an adult visit to the nest. Mean daily SST values (calculated from half hour readings) were obtained from the Australian Institute of Marine Science, Half-Tide Rocks remote weather station $\left(23^{\circ} 09^{\prime} \mathrm{S}, 150^{\circ} 56^{\prime} \mathrm{E}_{;} 125 \mathrm{~km}\right.$ NE of Heron Island)

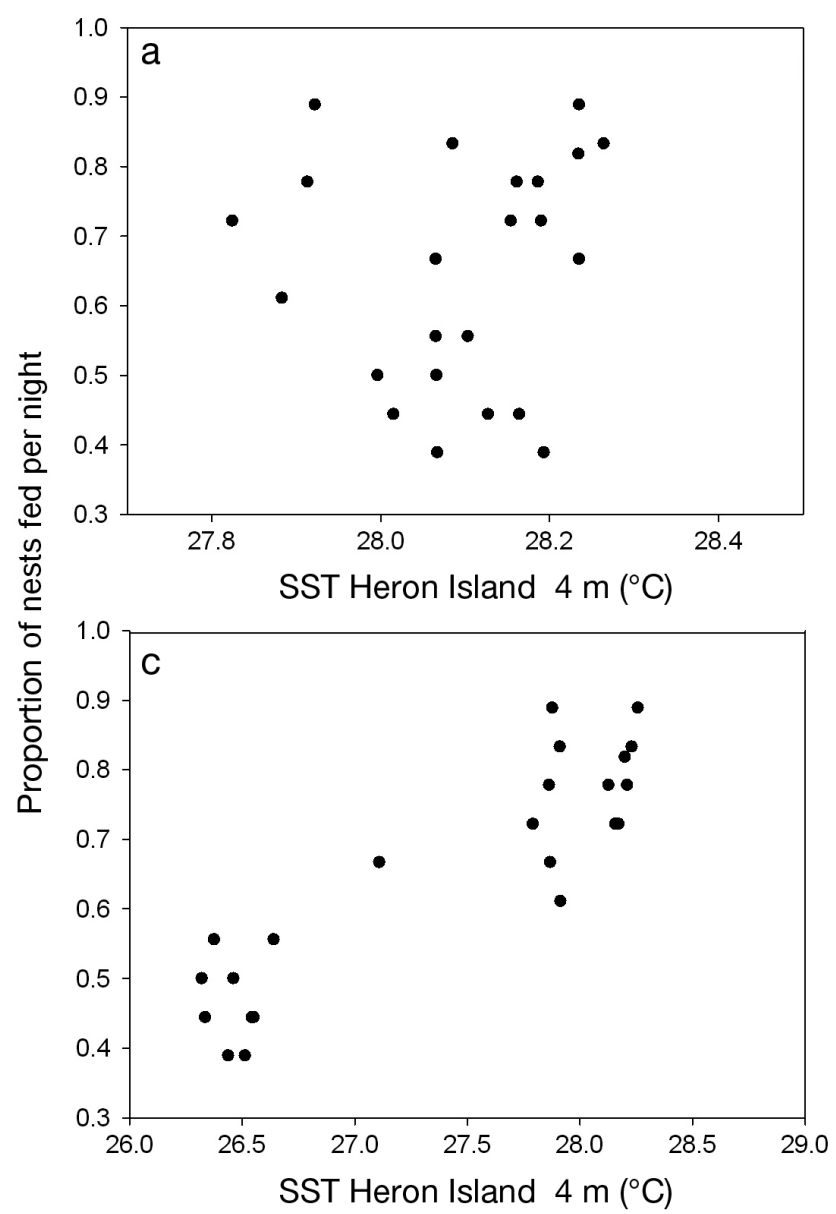

1999), by relatively cooler oceanic EAC waters entraining warmer lagoonal surface waters. From 11 to 19 February, the deeper penetrating ocean colour signal (O'Reilly et al. 2000) showed the cyclonic lee circulation to expand and mature (Fig. 2c), further impinging the Capricorn-Bunker reefs. During this phase a pronounced warming of the surface layer dominated the SST signal (Fig. 2d), effectively capping waters at depth. The cyclonic eddy appeared to have decreased in intensity during the latter part of February (Fig. 2e), when the relatively cooler EAC waters were again visible in the surface layer (Fig. 2f).

Heron Island is part of the Capricorn-Bunker group of reefs that extend along the outer edge of the continental shelf near the southwestern periphery of the Capricorn Eddy (Fig. 1). The wedge-tailed shearwater Ardenna pacifica nesting colony on Heron Island is located very near the southwest coastal edge of the bathymetric terrace feature where the Capricorn Eddy is situated. Here, the coastward-directed flow on the inshore side of the eddy will tend to push

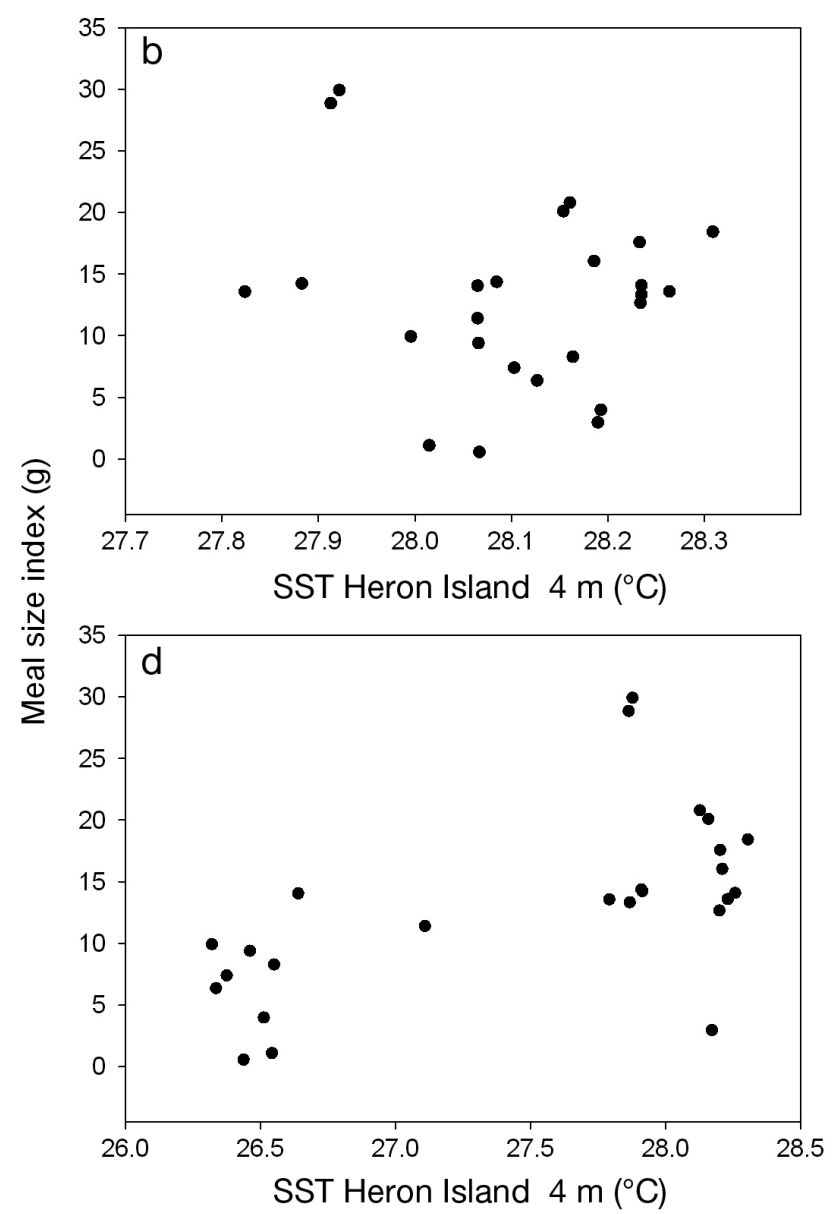

Fig. 6. Relationships between: proportion of nests fed per night and daily average sea-surface temperature (SST) south of Heron Island at (a) $4 \mathrm{~m}$ and (c) $35 \mathrm{~m}$ and average chick meal size per night and SST south of Heron Island at (b) $4 \mathrm{~m}$ and (d) $35 \mathrm{~m}$. Refer to Fig. 3 for temperature logger details 
oceanic water onto the shelf and into the reef zone (Weeks et al. 2010). Moreover, the quasi-geostrophic circulation around the eddy circumference will have the additional effect of locally raising the sea level near the eddy edge, so as to locally reduce the larger scale downward offshore slope of the sea surface produced by the density differences between the generally fresher, often warmer (in summer) lagoon waters and the more saline oceanic waters. The difference may be intensified during extreme warm episodes when the shallower, more continentally influenced reef waters may experience relatively greater warming than the oceanic waters beyond the continental shelf.

Thus, during intervals of relatively strong eddy circulation, there would be a greater tendency for cool, upwelled oceanic waters to be pushed toward the coast by the intensified combination of outwardly directed coriolis and centrifugal forces associated with strong eddy circulation (Bakun 1996). Accordingly, there would be a tendency for these more dense upwelled oceanic waters to undermine and slide beneath the less dense lagoon waters. This favours a stratified water column (as seen in the midFebruary portion of the time series shown in Fig. 3a) in the reef zone as opposed to the rather uniformly warm, tidally mixed water column characteristic of lagoon waters (early and late February portions of Fig. 3a). Stratification would be even further enhanced during periods of low wind and high insolation typically experienced during coral bleaching periods (Glynn 1993, Obura 2005) where water column mixing is limited causing surface-layer warming. The abrupt onset of stratification during February 2006 (Fig. 3a), however, would appear to be related to an intrusion of cooler, denser waters at depth rather than to any significant change in wind stress (Fig. 3b).

Prey availability to shearwaters significantly decreased during the period of stratification and the intrusion of the cooler, denser waters at depth in mid-February. Prey availability also clearly increased again following this episode, indicating that the loss of prey was associated with a short-term vertical and/or horizontal redistribution of prey or subsurface predators, rather than an overall decrease in productivity. Previous studies have shown that forage fish communities are structured along temperature and salinity gradients (e.g. Abookire \& Piatt 2005), implying that shifts in these gradients will alter forage fish distributions. Many types of fishes exhibit a distinct disinclination to traverse abrupt temperature gradients, or to pass through narrow thermoclines into low oxygenated waters (Bakun 2006). This is one reason, for example, that purse seining tends to be an effective fishing method only where a shallow thermocline exists to prevent encircled fish from diving below the net before the purse can be drawn closed beneath them. Also, it is possible that during anomalous episodes of intensified surface warming such as the 2005 to 2006 event in the southern GBR, pelagic forage fish might be found deeper as they seek the cooler temperatures to which they are more accustomed (Bakun 2006). Accordingly, during times when the water column is highly stratified (such as the mid-February portion of the time series shown in Fig. 3a), it is possible that the small pelagic forage fishes that are preyed upon by shearwaters may remain in the deeper layers where the birds may have difficulty in detecting and capturing them. Alternatively, increased stratification at depth may change the dynamics between forage fish and subsurface predators such that predators no longer feed by driving prey against the surface where foraging seabirds can access them. These 2 possibilities are not mutually exclusive and either scenario would account for the poor chick provisioning observed during the mid-February 2006 period (Figs. 4, $5 \& 6)$.

The foraging ecology of seabirds such as the wedge-tailed shearwater shows a high degree of dependence on oceanographic dynamics. Understanding how these dynamics will change over the coming decade and century will give us insight into how populations will fare as the climate changes. Climate model results suggest a southward shift and spin-up of the South Pacific gyre, including a strengthening of the EAC flow (Cai et al. 2005). Thus, one might envision more energetic driving of the Capricorn Eddy (Steinberg 2007). In one sense, this might be perceived as good news with respect to flushing of the deeper zones of the affected coral reefs. However, it may represent increasing challenges for nesting seabird populations within the Capricorn-Bunker group of islands given that it is likely to increase the extent of water column stratification and hence reduce access to prey. With the apparent collapse of forage success during the exceptionally warm conditions of 1998 and 2002, these types of changes could severely impact reproductive success. How these different impacts on the feeding and reproductive ecology of seabirds unfold and interact is likely to play an important role in whether or not these populations persist within the low-lying islands of the southern GBR. 
Acknowledgements. We gratefully acknowledge the NASA Ocean Biology Processing Group for provision of moderate resolution imaging spectroradiometer satellite data, and Andrew Bakun for valuable advice and encouragement. Funding for this study was provided by the Australian Government's Marine and Tropical Sciences Research Facility, National Environmental Research Program and the Australian Research Council Linkage Grant LP0562157. In situ data was collected with the assistance of the NASA Interdisciplinary Program, Grant NNG04GO90G.

\section{LITERATURE CITED}

Abookire AA, Piatt JF (2005) Oceanographic conditions structure forage fishes into lipid-rich and lipid-poor communities in lower Cook Inlet, Alaska, USA. Mar Ecol Prog Ser 287:229-240

Bakun A (1996) Patterns in the ocean: ocean processes and marine population dynamics. University of California Sea Grant, San Diego, CA, in cooperation with Centro de Investigaciones Biológicas de Noroeste, La Paz, Baja California Sur

Bakun A (2006) Fronts and eddies as key structures in the habitat of marine fish larvae: opportunity, adaptive response and competitive advantage. Sci Mar 70:105-122

Brown OB, Minnett PJ (1999) MODIS infrared sea surface temperature algorithm. In: Algorithm Theoretical Basis Document, V20. University of Miami, Miami, FL, available at http://modis.gsfc.nasa.gov/data/atbd/ocean_atbd.php

Cai W, Shi G, Cowan T, Bi D, Ribbe J (2005) The response of the Southern Annular Mode, the East Australian Current, and the southern mid-latitude ocean circulation to global warming. Geophys Res Lett 32:L23706, doi: 10.1029/2005GL024701

Congdon BC, Krockenberger AK, Smithers BV (2005) Dualforaging and co-ordinated provisioning in a tropical Procellariiform, the wedge-tailed shearwater. Mar Ecol Prog Ser 301:293-301

Congdon BC, Erwin CA, Peck DR, Baker GB, Double MC, O'Neill P (2007) Vulnerability of seabirds on the Great Barrier Reef to climate change. In: Johnson JE, Marshall PA (eds) Climate change and the Great Barrier Reef: a vulnerability assessment. Great Barrier Reef Marine Park Authority and Australian Greenhouse Office, Townsville, p 427-464

$>$ Devney CA, Short M, Congdon BC (2009) Sensitivity of tropical seabirds to El Niño precursors. Ecology 90:1175-1183

> Devney CA, Caley MJ, Congdon BC (2010) Plasticity of noddy parents and offspring to sea-surface temperature anomalies. PLoS ONE 5:e11891

> Durant JM, Anker-Nilssen T, Stenseth NC (2003) Trophic interactions under climate change fluctuations: the Atlantic puffin as an example. Proc R Soc Lond B Biol Sci 270: 1461-1466

Erwin CA, Congdon BC (2007) Day-to-day variation in sea-

Editorial responsibility: Rory Wilson,

Swansea, UK surface temperature reduces sooty tern (Sterna fuscata) foraging success on the Great Barrier Reef, Australia. Mar Ecol Prog Ser 331:255-266

> Glynn PW (1993) Coral reef bleaching: ecological perspectives. Coral Reefs 12:1-17

Inchausti P, Guinet C, Koudil M, Durbec JP and others (2003) Inter-annual variability in the breeding performance of seabirds in relation to oceanographic anomalies that affect the Crozet and the Kerguelen sectors of the southern ocean. J Avian Biol 34:170-176

Kleypas JA, Burrage DM (1994) Satellite observations of circulation in the southern Great Barrier Reef, Australia. Int J Remote Sens 15:2051-2063

Middleton J, Coutis P, Griffin D, Macks A, McTaggart A, Merrifield M, Nippard G (1994) Circulation and water mass characteristics of the southern Great Barrier Reef. Mar Freshw Res 45:1-18

O'Reilly JE, Maritorena S, O'Brien MC, Siegel DA and others (2000) SeaWiFS postlaunch calibration and validation analyses, Part 3. In: Hooker SB, Firestone ER (eds) NASA Tech Memo 2000-206892, Vol 11, NASA Goddard Space Flight Center, Greenbelt, MD

$>$ Obura DO (2005) Resilience and climate change: lessons from coral reefs and bleaching in the western Indian Ocean. Estuar Coast Shelf Sci 63:353-372

> Peck DR, Congdon BC (2005) Colony-specific foraging behaviour and co-ordinated divergence of chick development in the wedge-tailed shearwater Puffinus pacificus. Mar Ecol Prog Ser 299:289-296

Peck DR, Smithers BV, Krockenberger AK, Congdon BC (2004) Sea surface temperature constrains wedge-tailed shearwater foraging success within breeding seasons. Mar Ecol Prog Ser 281:259-266

Smithers BV, Peck DR, Krockenberger AK, Congdon BC (2003) Elevated sea-surface temperature, reduced provisioning and reproductive failure of wedge-tailed shearwaters (Puffinus pacificus) in the southern Great Barrier Reef, Australia. Mar Freshw Res 54:973-977

Steinberg C (2007) Impacts of climate change on the physical oceanography of the Great Barrier Reef. In: Johnson JE, Marshall PA (eds) Climate change and the Great Barrier Reef: a vulnerability assessment. Great Barrier Reef Marine Park Authority and Australian Greenhouse Office Australia, Townsville, p 51-74

> Stenseth NC, Mysterud A (2002) Climate, changing phenology, and other life history traits: nonlinearity and matchmismatch to the environment. Proc Natl Acad Sci USA 99:13379-13381

Weeks S, Bakun A, Steinberg C, Brinkman R, Hoegh-Guldberg O (2010) The Capricorn Eddy: a prominent driver of the ecology and future of the southern Great Barrier Reef. Coral Reefs 29:975-985

> Woodhead PMJ (1970) Sea surface circulation in the southern region of the Great Barrier Reef, Spring 1966. Aust J Mar Freshw Res 21:89-102

Submitted: January 15, 2013; Accepted: May 2, 2013

Proofs received from author(s): August 7, 2013 